\section{AB0643 CLINICAL AND ANALYTICAL DESCRIPTION OF A DERMATOMYOSITIS SERIES OF PATIENTS}

Jordi Camins-Fàbregas ${ }^{1}$, Clara Esteve-Cols ${ }^{2}$, Ivette Casafont-Solé ${ }^{1}$, Lourdes Mateo ${ }^{1}$, Laia Gifre ${ }^{1}$, Anne Riveros ${ }^{1}$, Maria Aparicio-Espinar ${ }^{1}$, Annika Nack ${ }^{1}$, Melania Martínez-Morillo', Clara Sangüesa-Gomez ${ }^{1}$,

Anahy Brandy-Garcia ${ }^{1}$, Águeda Prior-Español ${ }^{1}$, Mónica Munera-Campos ${ }^{3}$ Eva Martinez-Cáceres ${ }^{2}$, Isabel Bielsa-Marsol ${ }^{3}$, Josep Roca ${ }^{4}$, Alejandro Olive ${ }^{1}$, Quirant-Sánchez Bibiana ${ }^{2}$, Susana Holgado ${ }^{1}{ }^{1}$ Hospital Universitari Germans Trias i Pujol, Rheumatology, Badalona, Spain; ${ }^{2}$ Hospital Universitari Germans Trias i Pujol, Immunology, Badalona, Spain; ${ }^{3}$ Hospital Universitari Germans Trias i Pujol, Dermatology, Badalona, Spain; ${ }^{4}$ Hospital Universitari Germans Trias i Pujol, Epidemiology, Badalona, Spain

Background: Dermatomyositis (DM) is an idiopathic inflammatory myopathy. The recent years has increased its knowledge thanks to best characterization of myositis-specific antibodies that correlate with different clinical phenotypes.with different clinical phenotypes.

Objectives: To describe the clinical and analytical features of a series of dermatomyositis: clinical debut, clinical manifestations as well as the treatments received and the evolution of the disease.

Methods: Patients diagnosed of dermatomyositis in a tertiary hospital between the years 1978-2018 according to the criteria of Bohan and Peter (1975) and according to Dalakas' classification criteria (2015). Clinical, analytical and immunological profile data were collected, as well as treatments received and the evolution of the disease.

Results: A total of 59 inflammatory myopathies diagnosed between the years 1985 and 2018 were included. 46 were dermatomyositis (78\%), 9 polymyositis (15\%) and 4 necrotizing myositis (7\%). 69\% were women and $22 \%$ were smokers. Clinic started at $54 \pm 17$ years. The initial manifestation was pulmonary in $26.7 \%$ followed by cutaneous manifestations $(24.4 \%)$ and the muscular $(22.2 \%)$, while a $17.8 \%$ started skin and muscular manifestations at the same time. $45.5 \%$ behaved like a myopathic DM while a $28 \%$ as amyopathic DM and antisynthetase syndrome respectively. 38\% presented interstitial involvement being the most common non-specific interstitial pneumonitis $(76 \%)$ followed by usual interstitial pneumonitis $(17 \%)$. In these patients,

DLCO was decreased (mean of $58.9 \%$ and 13.2) as well as the FVC (average of $58 \%, 2.5 \mathrm{~L}$ ). $73.3 \%$ presented cutaneous involvement being the most common manifestations the Gottron papules (37.8\%) and the heliotrope rash $(35.6 \%)$, and up to $27 \%$ had cuticular affectacion. $64 \%$ had muscle involvement, afecting proximal and symmetrical. Neck flexors were affected in a $38 \%$ of patients while $20 \%$ had dysphagia.Only 3 patients presented dysphonia $(7 \%)$ and 2 myocarditis

Analytical data

\begin{tabular}{lc}
\hline Muscular enzyimes & \\
\hline CK & $821 \pm 1260 \mathrm{U} / \mathrm{mL}$ \\
LDH & $425 \pm 300 \mathrm{U} / \mathrm{L}$ \\
Aldolase & $11.5 \pm 11 \mathrm{U} / \mathrm{L}$ \\
Acute phase reactants & $30 \pm 23 \mathrm{~mm}$ \\
ESR & $13 \mathrm{mg} / \mathrm{L} \pm 25$ \\
RCP & \\
Myositis specific antibodies & $27 \%$ \\
AntiJo1 & $18 \%$ \\
MDA5 & $15 \%$ \\
SAE1/2 & \\
\hline
\end{tabular}

Conclusion: $80 \%$ received corticotherapy at a dose of $\mathrm{mg} / \mathrm{kg} / \mathrm{day}$ and $20 \%$ required high doses of metilprednisolone due to muscular involvement or pulmonary. $18 \%$ immunoglobulins and $11 \%$ cyclophosphamide. As maintenance $80 \%$ received disease modifiying antirheumatic drug in addition to corticosteroid therapy in descending doses (azathioprine 22\%, dolquine $15 \%$, tacrolimus $13.3 \%$, rituximab $11 \%$ ) due to muscle $(29.9 \%)$, cutaneous $(24.4 \%)$ and pulmonary involvement $(22.2 \%)$. As complications, 2 cases of the syndrome were registered hemophagocytic Virtually all patients they presented pulmonary hypertension (mean $34 \pm 12 \mathrm{mmHg}$ ). 5 patients $(11.1 \%)$ were diagnosed with neoplasia, two of them after the diagnosis of DM. The mortality was $24 \%$. 3 patients died due to a rapidly progressive pneumonitis, another 2 due to alveolar hemorrhage and three of them due to complication of the neoplastic disease.

Dermatomyositis occurs in a variable way, with predominance of pulmonary, skin and muscle manifestations. They require corticotherapy and immunosuppressive treatment for maintenance, even so, mortality is high. Disclosure of Interests: None declared DOI: 10.1136/annrheumdis-2019-eular.4086
AB0644

RESULTS OF A TRAINING COURSE FOR CALCULATION OF THE MODIFIED RODNAN SKIN SCORE IN SCLERODERMA

Gerçek Can ${ }^{1}$, Aydan Köken Avşar ${ }^{1}$, Sinem Burcu Kocaer ${ }^{1}$, Gökçe Kenar ${ }^{2}$, Dilek Solmaz ${ }^{3}$, Handan Yarkan-Tuğsal ${ }^{4}$, Duygu Temiz Karadağ ${ }^{5}$,

Neslihan Gökçen ${ }^{6}$, Servet Yolbaş ${ }^{7}$, Hakan Babaoglü ${ }^{8}$, Alper Yıldırım ${ }^{9}$, Müçteba Enes Yayla ${ }^{10}$, illyas Ercan Okatan ${ }^{10}$, Alper Sarı ${ }^{11}$, Didem Arslan Taş ${ }^{12}$, Fatos Onen ${ }^{1}$, Süleyman Serdar Koca ${ }^{13}$, Ali Akdoğan ${ }^{11}$, Merih Birlik ${ }^{1} .{ }^{1}$ Dokuz Eylul University Faculty of Medicine, Rheumatology, Izmir, Turkey, ${ }^{2}$ Mardin Devlet Hastanesi, Rheumatology, Mardin, Turkey, ${ }^{3}$ Izmir Katip Çelebi University, Rheumatology, Izmir, Turkey; ${ }^{4}$ Ağrı Devlet Hastanesi, Rheumatology, Ağrı, Turkey ${ }^{5}$ Canakkale Devlet Hastanesi, Rheumatology, Çanakkale, Turkey; ${ }^{6}$ Çukurova University, Rheumatology, Adana, Turkey, ${ }^{7}$ Inonu Universitesi, Rheumatology, Elazığ, Turkey; ${ }^{8}$ Gazi University, Rheumatology, Ankara, Turkey; ${ }^{9}$ Erciyes University, Rheumatology, Kayseri, Turkey; ${ }^{10}$ Ankara University, Rheumatology, Ankara, Turkey; ${ }^{11}$ Hacettepe University, Rheumatology, Ankara, Turkey; ${ }^{12}$ Çukurova Üniversitesi, Rheumatology, Adana, Turkey; ${ }^{13}$ Firat University, Rheumatology, Elazığ, Turkey

Background: Scleroderma is a connective tissue disease that is characterized by fibrosis of the skin. The modified Rodnan Skin Score (mRSS) is a measure generally used to assess the skin thickness in patients with scleroderma.Data on the effectiveness of the mRSS training courses differ in the literature.

Objectives: The objective of our study was to evaluate the effectiveness of the mRSS training course in rheumatology fellows in the rheumatology departments.

Methods: The study included 6 fellows from the departments of rheumatology.Participants were given a 1-hour-long theoretical training, including dermal involvement, and mRSS assessment by 3 rheumatology experts experienced in scleroderma, which was followed by an applied training on 4 patients for one-hour.Participants scored two patients before and after training on a form, which included 17 domains with a total scorerange between "0" and " 51 ". Then using the SPSS15 software program, inter-rater reliability was assessed with intraclass correlation(ICC) analysis for both pre- and post-training mRSS.Fleiss' kappa was used to measure the degree of agreement according to 12 Rodnan score areas before and after the training.

Results: The ICC value for pre-training and post-training total Rodnan scores was 0.867 (95\% Cl-0.625-1.00, $\mathrm{P}=0.05)$, and $0.905(95 \% \mathrm{Cl} 0.045$ $1.00, \mathrm{P}=0.02$ ), respectively. Individual analysis of score areas showed that after the training there was an increase in degree of agreement in some of these areas, while there was no difference in one area, and it decreased in others (Table 1).

Table 1: The ICC value and percentage of agreement for pre-training and post-training total

\begin{tabular}{|c|c|c|c|c|}
\hline \multirow[b]{2}{*}{ Body zeas } & \multicolumn{2}{|l|}{ Pre-trining } & \multicolumn{2}{|l|}{ Post-training } \\
\hline & $\begin{array}{l}\text { Fleis's Kappa } \\
\text { (cos CD) }\end{array}$ & Agreemen, \% & $\begin{array}{l}\text { Fleis's Kappa } \\
\text { (cos GA) }\end{array}$ & Agreement, \% \\
\hline Right fingers & $\begin{array}{l}0.38 \\
(0.003,0.73)\end{array}$ & 63.3 & $\begin{array}{l}0.60 \\
(-0.18,1.00)\end{array}$ & 70.0 \\
\hline Let fingers & $\begin{array}{l}0.42 \\
(0.16,0.68)\end{array}$ & 56.6 & $\begin{array}{l}0.29 \\
(0.29,0.29)\end{array}$ & 46.6 \\
\hline Right hand & $\begin{array}{l}0.02 \\
(0.02,0.02)\end{array}$ & 26.6 & $\begin{array}{l}0.11 \\
(-0.06,0.29)\end{array}$ & 33.3 \\
\hline Left hand & $\begin{array}{l}0.16 \\
(-0.11,0.42)\end{array}$ & 36.6 & $\begin{array}{l}0.16 \\
(-0.11,0.42)\end{array}$ & 36.6 \\
\hline Right foreamm & $\begin{array}{l}0.29 \\
(0.29,0.29)\end{array}$ & 46.6 & $\begin{array}{l}0.02 \\
(0.02,0.02)\end{array}$ & 26.6 \\
\hline Leff foream & $\begin{array}{l}0.29 \\
(0.29,0.29)\end{array}$ & 46.6 & $\begin{array}{l}0.02 \\
(0.02,0.02)\end{array}$ & 26.6 \\
\hline Right upper amm & $\begin{array}{l}0.11 \\
(-0.06,0.29)\end{array}$ & 33.3 & $\begin{array}{l}-0.22 \\
(-0.11,0.06)\end{array}$ & 233 \\
\hline Letêt upper am & $\begin{array}{l}0.24 \\
(0.16,0.33)\end{array}$ & 43.3 & $\begin{array}{l}0.02 \\
(0.02,0.02)\end{array}$ & 26.6 \\
\hline Face & $\begin{array}{l}0.24 \\
(0.16,0.33)\end{array}$ & 43.3 & $\begin{array}{l}0.02 \\
(0.02,0.02)\end{array}$ & 26.6 \\
\hline Anterios chest & $\begin{array}{l}0.24 \\
(0.16,0.33)\end{array}$ & 43.3 & $\begin{array}{l}0.16 \\
(-0.11,0.42)\end{array}$ & 36.6 \\
\hline Abdomen & $\begin{array}{l}0.16 \\
(-0.11,0.42)\end{array}$ & 36.6 & $\begin{array}{l}0.11 \\
(-0.06,0.299\end{array}$ & 33.3 \\
\hline Right thigh & $\begin{array}{l}0.02 \\
(0.02,0.02)\end{array}$ & 26.6 & $\begin{array}{l}0.29 \\
(0.29,0.29)\end{array}$ & 46.6 \\
\hline Left thigh & $\begin{array}{l}0.02 \\
(0.02,0.02)\end{array}$ & 26.6 & $\begin{array}{l}0.20 \\
(-0.50,0.90)\end{array}$ & 40.0 \\
\hline Right leg & $\begin{array}{l}0.38 \\
(0.003,0.73)\end{array}$ & 53.3 & $\begin{array}{l}0.24 \\
(0.16,0.33)\end{array}$ & 433 \\
\hline
\end{tabular}

Conclusion: Several studies have demonstrated the applicability, reliability, and validity of mRSS, a measure of dermal involvement, and that evaluation of the score requires experience, and an attentive learning process.In the literature, the inter-rater ICC values during previous training courses are reported to range between 0.378 and $0.92(1)$. These studies show differences in terms of the number and experience of participants, 